\title{
Geotrichopsis mycoparasitica as a destructive mycoparasite
}

\author{
S.S. TZEAN \\ Department of Plant Pathology and Entomology, National Taiwan University, Taipei, Taiwan, 10764, R.O.C. \\ R. H. ESTEY \\ Department of Plant Sciences, Macdonald College of McGill University, Ste Anne de Bellevue, Quebec, H9X 1CO. Canada
}

\begin{abstract}
Geotrichopsis mycoparasitica in vitro in dual cultures was shown to be a biotrophic destructive mycoparasite, capable of parasitizing twenty seven fungi, including some oomycetes, zygomycetes and hyphomycetes, with varied susceptibility. The parasite usually produced short lateral hyphal branches or clamp-like structures to entwine or clasp the host hyphae or fruiting structures. Infection pegs initiated from hyphal tips, appressoria or clamps penetrated the host cells and occasionally formed infection vesicles or trophic hyphae. Infection was apparently accomplished by both mechanical force and enzymatic activity as shown by transmission and scanning electron microscopy. The attacked host's cell wall disintegrated, membranes and organelles were disrupted, and the host hyphae lysed eventually. Colonies of highly susceptible hosts were largely destroyed within $7-10 \mathrm{~d}$ at $20-35{ }^{\circ} \mathrm{C}$ under balanced nutritional conditions.
\end{abstract}

The terms mycoparasitism and mycoparasite were coined by Butler (1957) to denote the parasitism or parasite of one fungus on another fungus. In accordance with the mode of parasitism, mycoparasites were separated into two major categories, the biotrophic (balanced) mycoparasites and the necrotrophic (destructive) mycoparasites (Barnett \& Binder, 1973). The biotrophic mycoparasites primarily comprise contact and haustorial parasites, in which absorption of nutrients from living fungal hosts is via plasmodesmata, large pore connexions, or haustoria (Berry \& Barnett, 1957; Hoch, $1977 a, b, 1978$ ). The biotrophic mycoparasites usually show host specificity and cause little damage to their hosts (Barnett \& Binder, 1973).

During examination of nemafode-trapping in Petri dishes, the nematophagous fungi Arthrobotrys oligospora, $A$. robusta and $A$. superba were found to be parasitized by an unidentified arthrosporic fungus. The mycoparasite was newly described as Geotrichopsis mycoparasitica Tzean \& Estey (Tzean \& Estey, 1991). Here we describe its interaction with fungal hosts.

\section{MATERIALS AND METHODS}

Geotrichopsis mycoparasitica and fifty potential fungal hosts were maintained on Difco corn meal agar. For determining the host range and mode of parasitism, three $2 \mathrm{~mm}$ agar discs were excised from 2 -wk-old culture plates and placed in a line opposite three discs of a host fungus on half-strength potatodextrose agar plates (Difco). Each treatment had 4 replicates and experiments were repeated at least twice. The hostparasite interactions were examined with a light microscope after 7-10 d. The relative susceptibility of the hosts was rated from 0 (immune or non-host) to 4 (highly susceptible) as explained in Table 1. For determining the mode of parasitism and host-parasite interface, transmission and scanning electron microscopy were used. Small pieces of agar discs were cut from a dual culture plate where the mycoparasitism was most extensive and the discs were processed for electron microscopy as previously described (Tzean \& Estey, 1978). Effects of culture media, $\mathrm{pH}$, and temperature on parasitism were studied using A. superba, Cunninghamella elegans, Fusarium oxysporum, F. roseum and Rhizoctonia solani as hosts. The media were $2 \%$ water agar (WA), half-strength potato dextrose agar (PDA), Czapek's solution agar (CSA), corn meal agar (CMA), and malt-extract agar (MEA) (Difco). Half-strength PDA was adjusted to $\mathrm{pH} 4 \cdot 5,5 \cdot 5,6 \cdot 0,6 \cdot 4$, or $7 \cdot 4$ by Mcllvaine's buffer (Clark, 1928), and plates of unadjusted half-strength PDA were incubated at $10^{\circ}, 15^{\circ}, 20^{\circ}, 25^{\circ}$ and $35^{\circ}$. In comparisons of media and $\mathrm{pH}$, all plates were incubated at $25^{\circ}$ in darkness and examined after 7-10 d.

\section{RESULTS}

\section{Host range and mode of parasitism}

Of the 50 potential fungal hosts, 23 were immune or nonhost, and 27 were invaded by G. mycoparasitica, but showed varied susceptibility (Table 1). So far, all the tested members of the ascomycetes (e.g. Byssochlamys fulva, Emericella variecola, Sordaria fimicola) and basidiomycetes (Heterobasidion annosum, Polyporus resinosus) were immune to or non-hosts of $G$. mycoparasitica. According to the response, the immune or nonhost fungi could be separated into three groups: Diplodia zeae, 
Table 1. Susceptibility of fungi tested as potential hosts of Geotrichopsis mycoparasitica

\begin{tabular}{|c|c|c|c|}
\hline & $\begin{array}{l}\text { Susceptibility } \\
\text { rating }^{*}\end{array}$ & & $\begin{array}{l}\text { Susceptibility } \\
\text { rating }\end{array}$ \\
\hline Absidia spinosa Lend. & 2 & Harposporium sp. & 0 \\
\hline Alternaria tenuis Nees & 1 & Drechslera sorokiniana (Sacc.) Subram. \& Jain & 0 \\
\hline Arthrobotrys dactyloides Drechsl. & 4 & Heterobasidion annosum (Fr.: Fr.) Bref. & 0 \\
\hline A. oligospora Fresen & 4 & Hyalostachybotrys sp. & 0 \\
\hline A. pyriformis (Jun.) Sche., Kend. \& Pramer & 4 & Matruchotia varians Boul. & 0 \\
\hline A. robusta Dudd. & 4 & Meria coniospora Drechsl. & 0 \\
\hline A. superba Corda X145B & 4 & Monacrosporium cionopagum (Drechsl.) Subram. & 2 \\
\hline Aspergillus niger van Tiegh. & 0 & Monocillium indicum Saks. & 0 \\
\hline Bactridiopsis sp. & 0 & Mortierella hygrophila Linn. & 4 \\
\hline Botrytis cinerea Pers.: Fr. & 1 & Nematoctonus leiosporus Drechsl. & 0 \\
\hline Byssochlamys fuloa Oliver \& Smith & 0 & Papulaspora dodgei Conn. & 4 \\
\hline Cladosporium sp. & 1 & Penicillum notatum West. & 0 \\
\hline Cunninghamella elegans Lend. & 4 & Periconia macrospinosa Lef. \& John. & 0 \\
\hline Dactylella candida (Nees) de Hoog \& v. Oorschot & 1 & Polyporus resinosus Sch.: Fr. & 0 \\
\hline D. haptotyla (Drechsl.) de Hoog \& v. Oorschot & 2 & Pythium dissotocum Drechsl. & 4 \\
\hline Diplodia zeae (Schw.) Lév. & 0 & P. monospermum Pringsh. & 4 \\
\hline Emericella variecola Berk. \& Br. & 0 & Rhizoctonia solani Kühn & 4 \\
\hline Fusarium oxysporum Schlecht. f. sp. lycopersici (Sacc.) & 4 & Rhizopus stolonifer (Ehrenb.: Fr.) Vuill. & 4 \\
\hline Snyder \& Hansen & & Sclerotium rolfsii Sacc. & 0 \\
\hline F. roseum Link emend Snyder \& Hansen & 1 & Sordaria fimicola (Rob.) Ces. \& de Not. & 0 \\
\hline Geotrichum candidum Link & 0 & Stachybotrys atra Corda & 0 \\
\hline Gliocladium roseum Bain. & 0 & Thielaviopsis paradoxa (de Seyn.) Höhn. & 4 \\
\hline Gliomastix sp. & 0 & Verticillium cimabarinum (Corda) Reinke \& Berth. & 0 \\
\hline Gongronella butleri (Lend.) Peyr. \& Dal Vesco & 3 & V. dahliae Kleb. & 1 \\
\hline Harposporium crassum Sheph. & 1 & Zygorhynchus sp. & 1 \\
\hline
\end{tabular}

* 0 , immune or non-host, with no parasitism; 1, resistant, slight parasitism observed, less than $10 \%$ of host colony at the advancing front was colonized; 2 , intermediate resistant, parasitism observed, $10-25 \%$ of host colony was overrun by the parasite; 3 , susceptible, widespread parasitism observed, $25-50 \%$ of the host colony was overrun by the parasite; 4 , highly susceptible, heavy parasitism observed, $50-100 \%$ of host colony was overrun by the parasite.

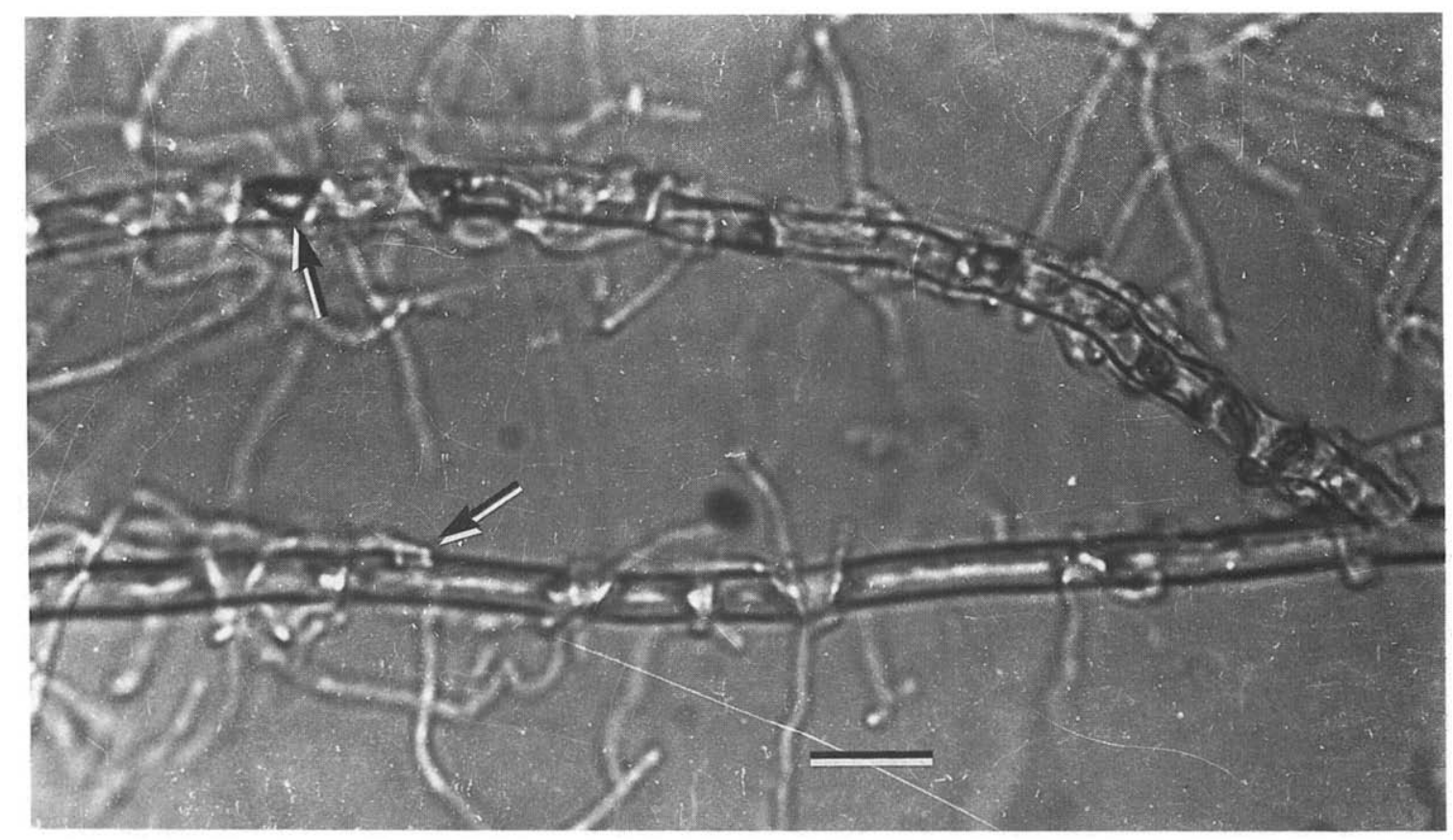

Fig. 1. Lateral hyphae of G. mycoparasitica touching or entwining the hyphae of Rhizoctonia solani. Arrows indicate abnormal vacuolation and places where penetration might take place. Bar, $10 \mu \mathrm{m}$.

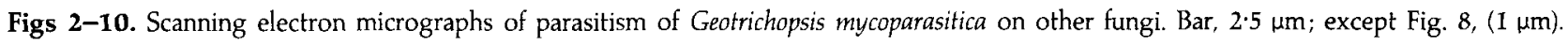

Figs 2-4. G. mycoparasitica attacks Fusarium roseum by short lateral hyphal branches, which penetrate (Figs 2, 3, arrow) or apparently collapse the host (Fig. 4). Fig. 5. A terminal knob-like appressorium produced by the parasite presses on and indents the cell wall of Rhizoctonia solani (arrow). Fig. 6. Finger-like clamp of G. mycoparasitica clasping the hyphae of Rhizopus stolonifer. Figs 7-9. Lateral hyphae of the parasite coiling around the host, Arthrobotrys oligospora, become torulose, stout, and some transform into intercalary or terminal irregularly-shaped appressoria (arrows). The attacked host cell wall shows partial disintegration (Fig. 9, arrows). Fig. 10. The vesicle and conidia of Cunninghamella elegans attacked and collapsed by the parasite (arrow). 

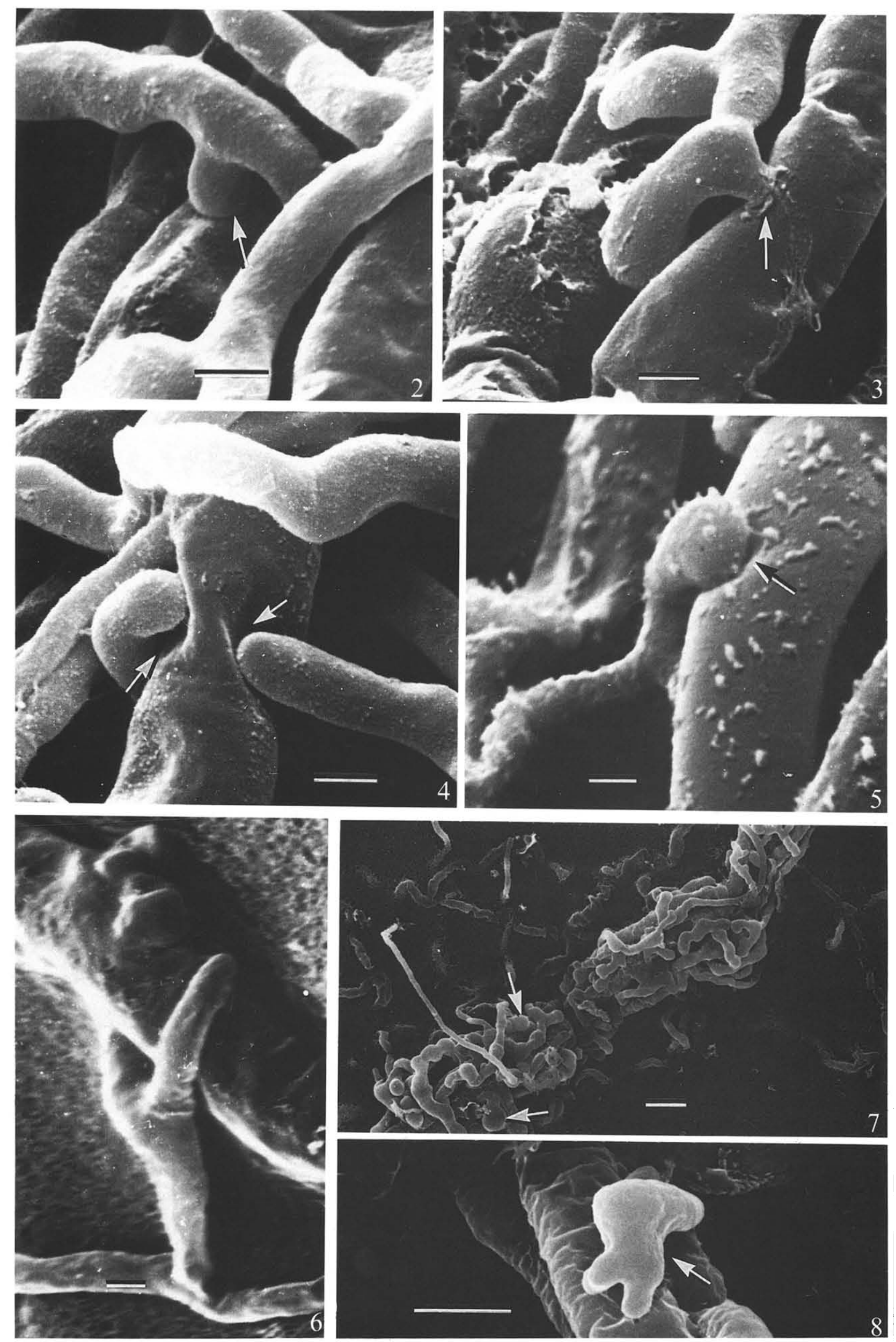

Figs 2-8. For caption see facing page. 

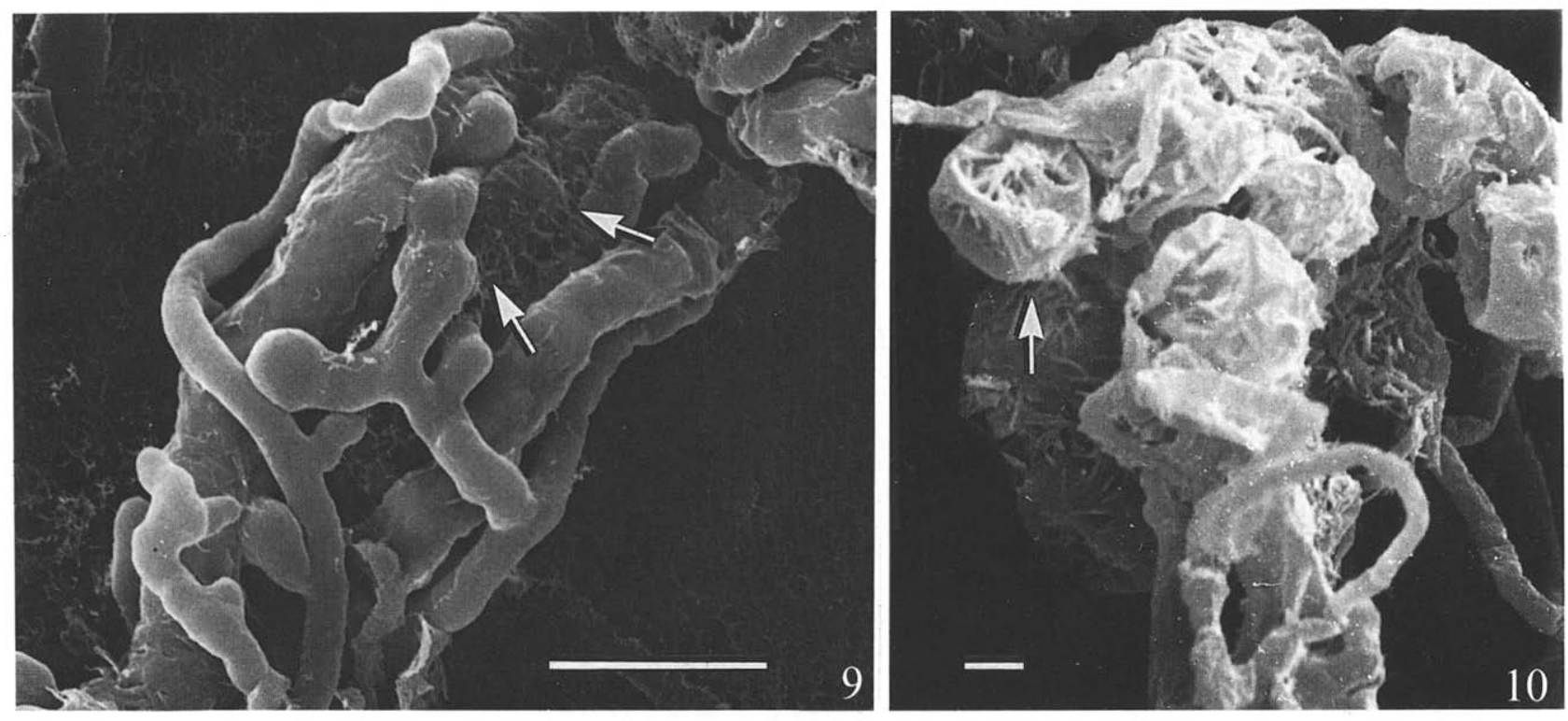

Figs 9-10. For caption see p. 264.

H. annosum and a Bactridiopsis sp. were commensal - their hyphae intermingled with G. mycoparasitica but showed no sign of abnormality; $P$. resinosus hyphae showed abnormal swelling and granulated cytoplasm when making contact with G. mycoparasitica, though no parasitism occurred - a case of unilateral antagonism or interference; Aspergillus niger, $E$. variecola, Penicillium notatum and Stachybotrys atra were mutally antagonistic - a clear demarcation zone existed in the dual culture plates. For the 27 host species 8 were resistant, 3 were intermediate-resistant, 1 was susceptible and 15 were highly susceptible. For F. roseum, one of the resistant hosts, parasitism was restricted to the initial contact zone, while in intermediate resistant hosts like Absidia spinosum and Monacrosporium cionopagum the parasite advanced a limited distance beyond the contact zone. The oomycetes, Pythium dissotocum and $P$. monospermum, most zygomycetes (C. elegans, Rhizopus stolonifer, Mortierella hygrophila), some nematode-trapping fungi and a few plant pathogens ( $R$. solani and Thielaviopsis paradoxa) were highly vulnerable to $G$. mycoparasitica; parasitism was heavy and their colonies were largely overgrown and destroyed by the parasite within 7-10 d.

Light microscopy of the host-parasite interactions indicated that G. mycoparasitica could attack the host hyphae, conidia or other fruiting structures such as sporangia and zygophores. Most often the invasion was achieved by short lateral branches, which were induced to develop and showed positive tropism, and touched or curled around the host hyphae or fruiting structures. Depending on the host, coiling could be very tight and intense-e.g. with Arthrobotrys dactyloides or loose as in the case of $C$. elegans. On several occasions, G. mycoparasitica gave rise to a clamp-like structure that clasped the host hyphae or conidia, for example with $M$. cionopagum or $A$. oligospora. The infection pegs which penetrated hosts could be initiated from unspecialized hyphal tips, clamp-like structures or appressoria. The appressoria could be a terminal knob-like structures, on short hyphal branches or intercalary irregular enlargements, somewhat bladder-like in shape, on the coiling hyphae. After penetration, the parasite formed infection vesicles or trophic hyphae which grew through the septa along the host hyphae and finally emerged from the host, as in the case of R. solani (Fig. 1). In host hyphae the cytoplasmic contents coagulated, became sparse, and eventually disintegrated and lysed.

Scanning electron microscopy revealed more details of the host-parasite interface and mode of attack (Figs 2-10). The parasite could penetrate $F$. roseum by an infection peg which was initiated from an apparently unspecialized lateral curling hypha (Fig. 2), or from a somewhat differentiated appressorium (Fig. 3). In the vicinity of the infection sites, the disruption and dissolution of the host cell wall was noticeable (Fig. 3), implying an enzymatic activity. The parasite was apparently capable of exerting mechanical force, as some host hyphae were crushed and indented (Figs 4-6, 8, 13). In the final stages, the invaded host hyphae exhibited extreme disruption and lysis (Figs 7, 9, 10). Transmission electron microscopy of $G$. $m y$ coparasitica- $R$. solani interactions showed that ultrastructure of the host remained intact in the early stages of infection (Fig. 11). In response to penetration, the host formed papillae in advance of the penetration peg and also deposited electrondense substances beneath it. In the later infection stages,

Figs 11-14. Parasitism by Geotrichopsis mycoparasitica on Rhizoctonia solani. Bar, $2.5 \mu \mathrm{m}$, except Fig. 12, (0.5 $\mu \mathrm{m})$.

Fig. 11. Longitudinal section revealing the invagination of host plasmalemma, formation of papillae ( $P$ ), infection sites, infection pegs (I) and appressorium-like structure $(A)$, produced by the parasite. Fig. 12. Cell-wall dissolved and disrupted at the point of contact with the knob-like appressorium $(\mathrm{A})$ of the parasite. Host plasmalemma invaginated to form papilla (P). Figs 13, 14. Host hyphae attacked or clasped by the lateral hyphae or finger-like clamp $(\mathrm{FC})$ of the parasite, showing papilla $(\mathrm{P})$ and altered host wall. 

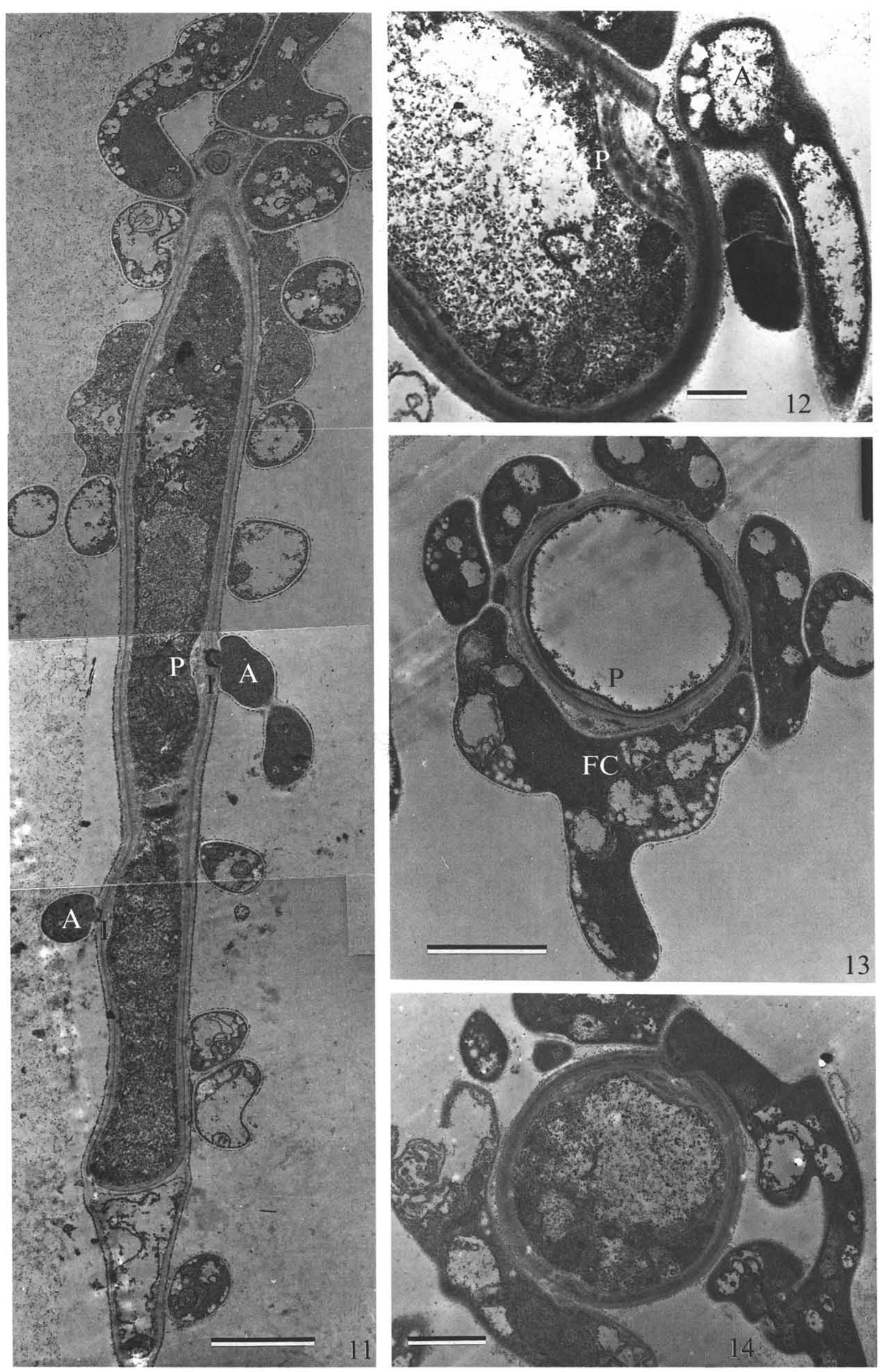

Figs 11-14. For caption see facing page. 
Table 2. Susceptibility rating ${ }^{*}$ of five host fungi to parasitism by Geotrichopsis mycoparasitica on dual cultures on water agar (WA), cornmeal agar (CMA), Czapek's solution agar (CSA), malt extract agar (MEA) or potato dextrose agar (PDA)

\begin{tabular}{|c|c|c|c|c|c|}
\hline & \multicolumn{5}{|c|}{ Susceptibility rating ${ }^{*}$} \\
\hline & WA & CMA & CSA & MEA & PDA \\
\hline Arthrobotrys superba & 2 & 2 & 1 & 4 & 4 \\
\hline Cunninghamella elegans & 2 & 2 & 2 & 4 & 4 \\
\hline $\begin{array}{l}\text { Fusarium oxysporum } \\
\text { f. sp. lycopersici }\end{array}$ & 1 & 1 & 0 & 0 & 4 \\
\hline Fusarium roseum & 1 & 1 & 0 & 1 & 1 \\
\hline Rhizoctonia solani & 2 & 2 & 1 & 4 & 4 \\
\hline
\end{tabular}

dissolution of the host cell wall became more conspicuous beneath knob-like appressoria, finger-like clamps or hookshaped structures (Figs 12-14). The host cytoplasmic contents were denatured and organelles destroyed (Fig. 12).

\section{Factors affecting parasitic activity}

The type of culture medium markedly affected the degree of parasitism, especially of highly susceptible hosts such as $A$. superba, $C$. elegans and $R$. solani. The hosts were heavily parasitized on PDA and MEA, less affected on CMA and WA, and least affected on CSA (Table 2). On CSA vegetative growth of the parasite was checked despite the presence of the essential nutrients for growth. For the resistant host, F. roseum, the type of medium had little effect on the degree of parasitism. All four susceptible hosts, A. superba, C. elegans, F. oxysporum f. sp. lycopersici and $R$. solani, had a susceptibility rating of ' 4 ' over the temperature range of $15-35^{\circ}$, but lower ratings $(1-3)$ at $10^{\circ}$. Lower $\mathrm{pH}(4 \cdot 5-5 \cdot 5)$ favoured the parasitism, whereas higher $\mathrm{pH}(7 \cdot 4)$ depressed the parasitism.

\section{DISCUSSION}

Geotrichopsis mycoparasitica has been shown in the present study to be a destructive mycoparasite. The mode of parasitism and host range of the parasite were comparable to several previously described necrotrophic mycoparasites such as Gliocladium roseum, G. virens Miller, Giddens \& Foster, Trichoderma harzianum Rifai, $T$. viride Pers.: Fr. and Schizophyllum commune Fr. (Barnett \& Lilly, 1962; Tu, 1980; Elad et al., 1983; Dennis \& Webster, 1971 b; Griffith \& Barnett, 1967; Tzean \& Estey, 1978). No evidence indicated that the parasite secretes antibiotics or toxic substances in advance of killing its hosts. Moreover most fungal hosts, especially highly susceptible ones, usually deposited electron-dense wall materials to prevent the ingrowth of the infection peg - at least in the early infection stages. So G. mycoparasitica could be a destructive biotrophic mycoparasite rather than a necrotrophic mycoparasite. In this respect G. mycoparasitica differed markedly from G. virens, Polyporus adustus Willd. ex Fr. and some Trichoderma spp. which usually produce diffusible enzymes or antibiotics (trichodermin, alamethicine, viridin) that act at a distance to kill the fungal host (Barnett \& Lilly,
1962; Griffith \& Barnett, 1967; Dennis \& Webster, $1971 a, b$; Elad et al., 1983, 1985; Sivan \& Chet, 1989).

G. mycoparasitica was able to invade a wide range of fungal hosts of varied cell wall structure and composition. Evidence obtained from electron microscopy indicated that the penetrated host cell wall was indented, deformed and dissolved. Apparently, a variety of extracellular, inducible wall-lytic enzymes might play a crucial role for the parasite to initiate infection. However, the nature of the lytic enzymes remains unclear and deserves further study. High glucanase, cellulase and chitinase activities have been detected in some destructive mycoparasites, e.g. T. harzianum, T. hamatum (Bon.) Bain. and Pythium nunn Lifshitz, Staghellini \& Baker and $P$. acanthicum Drechsler while parasitizing $R$. solani, $P$. aphanidermatum (Edson) Fitzp. or Sclerotium rolfsii Sacc. (Elad et al., 1983, 1985; Sivan \& Chet, 1989; Barak et al., 1985).

The determinants of host specificity, susceptibility and resistance to $G$. mycoparasitica are not yet known. When it encountered fungal hosts, especially of high susceptibility, $G$. mycoparasitica was stimulated to produce profuse short lateral branches and appressoria and showed a positive tropism toward the hosts. This has been discussed by Tsuneda \& Skoropad (1980) to account for the interactions between a destructive mycoparasite Nectria inventa Pethybridge and fourteen fungi associated with rapeseed. Recently Barak et al. (1985) suggested that lectins (agglutinins) act as a possible basis for specific recognition in the interactions of Trichoderma and $S$. rolfsii. The cell wall constituents can exert a great effect on the resistance and susceptibility of fungal hosts in both obligate biotrophic and facultative destructive mycoparasitism (Elad et al., 1985; Sivan \& Chet, 1989; Manocha, 1981; Manocha \& Golesorkhi, 1979, 1981). Also the cell wall and cellular constituents are dynamic and may change under different cultural conditions such as temperature, light, $\mathrm{pH}$, composition of medium, etc. Therefore it is not unexpected that these environmental factors can influence the susceptibility of fungal hosts to G. mycoparasitica.

This work was supported in part by a grant, NSC-79-0409B002-45, from National Science Council, R.O.C. The authors are indebted to $\mathrm{Mr} \mathrm{J}$. L. Chen and Miss W. F. Kao for typing the manuscript.

\section{REFERENCES}

Barak, R., Elad, Y., Mirelman, D. \& Chet, I. (1985). Lectins : a possible basis for specific recognition in the interaction of Trichoderma and Sclerotium rolfsii. Phytopathology 75, 458-462.

Barnett, H. L. \& Lilly, V. G. (1962). A destructive mycoparasite, Gliocladium roseum. Mycologia 54, 72-77.

Barnett, H. L. \& Binder, F. L. (1973). The fungal host-parasite relationship. Annual Review of Phytopathology 11, 273-292.

Berry, C. R. \& Barnett, H. L. (1957). Mode of parasitism and host range of Piptocephalis virginiana. Mycologia 49, 374-386.

Butler, E. E. (1957). Rhizoctonia solani as a parasite of fungi. Mycologia 49. 354-373.

Clark, W. M. (1928). The Determination of Hydrogen Ions. Baltimore: Williams \& Wilkins.

Dennis, C. \& Webster, J. (1971 a). Antagonistic properties of species-groups of Trichoderma. II. Production of volatile antibiotics. Transactions of the British Mycological Society 57, 41-48. 
Dennis, C. \& Webster, J. (1971b). Antagonistic properties of species-groups of Trichoderma. III. Hyphal interaction. Transactions of the British Mycological Society 57, 363-369.

Elad, Y., Chet, I., Boyle, P. \& Henis, Y. (1983). Parasitism of Trichoderma spp. on Rhizoctonia solani and Sclerotium rolfsii-scanning electron microscopy and fluorescence microscopy. Phytopathology 73, 85-88.

Elad, Y., Lifshitz, R. \& Baker, R. (1985). Enzymatic activity of the mycoparasite Pythium nunn during interaction with host and non-host fungi. Physiological Plant Pathology 27, 131-148.

Griffith, N. T. \& Barnett, H. L. (1967). Mycoparasitism by basidiomycetes in culture. Mycologia 59, 149-154.

Hoch, H. C. (1977a). Mycoparasitic relationships. III. Parasitism of Physalospora abtusa by Calcarisporium parasiticum. Canadian Joumal of Botany 55, 198-207.

Hoch, H. C. (1977b). Mycoparasitic relationships: Gonatobotrys simplex parasitic on Alternaria tenuis. Phytopathology 67, 309-314.

Hoch, H. C. (1978). Mycoparasitic relationships. IV. Stephanoma phaeospora parasitic on a species of Fusarium. Mycologia 70, 370-379.

Manocha, M. S. (1981). Host specificity and mechanism of resistance in a mycoparasitic system. Physiological Plant Pathology 18, 257-265.
Manocha, M.S. \& Golesorkhi, R. (1979). Host-parasite relations in a mycoparasite. V. Electron microscopy of Piptocephalis virginiana infection in compatible and incompatible hosts. Mycologia 71, 565-576.

Manocha, M.S. \& Golesorkhi, R. (1981), Host-parasite relations in a mycoparasite. VII. Light and scanning electron microscopy of interactions of Piptocephalis virginiana with host and non-host species. Mycologia 73, 976-987.

Sivan, A. \& Chet, 1. (1989). Degradation of fungal cell walls by lytic enzymes of Trichoderma harzianum. Joumal of General Microbiology 135, 675-682.

Tu, J. C. (1980). Gliocladium virens, a destructive mycoparasite of Sclerotinia sclerotiorum. Phytopathology 70, 670-674.

Tsuneda, A. \& Skoropad, W. P. (1980). Interactions between Nectria inventa, a destructive mycoparasite, and fourteen fungi associated with rapeseed. Transactions of the British Mycological Society 74, 501-507.

Tzean, S. S. \& Estey, R. H. (1978). Schizophyllum commune Fr. as a destructive mycoparasite. Canadian Joumal of Microbiology 24, 780-784.

Tzean, S. S. \& Estey, R. H. (1991). Geotrichopsis mycoparasitica gen. et. sp. nov. (Hyphomycetes), a new mycoparasite. Mycological Research 95, 13501354.

(Accepted 10 October 1991) 